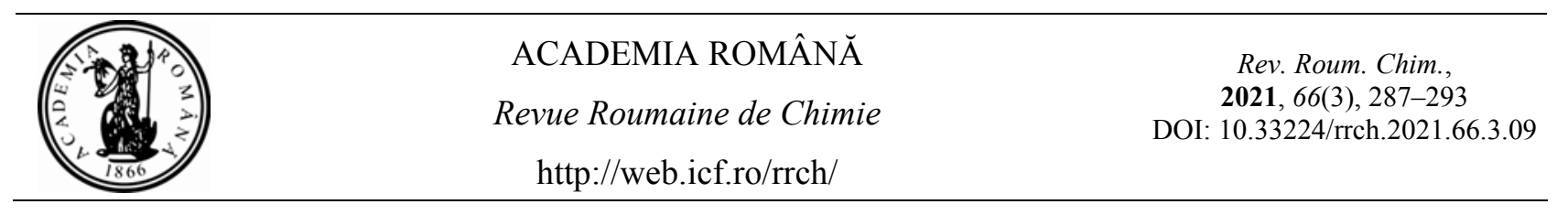

\title{
Ti-SBA-15 MESOPOROUS PHOTOCATALYSTS MODIFIED WITH LANTHANIDES FOR DEGRADATION OF DYES IN AQUEOUS SOLUTION**
}

\author{
Daniela NEGOESCU, Daniela Cristina CULITA, Irina ATKINSON, Veronica BRATAN, \\ Simona PETRESCU and Viorica PARVULESCU*
}

“Ilie Murgulescu” Institute of Physical Chemistry, Roumanian Academy, Splaiul Independentei 202, 060021, Bucharest, Roumania

New bimetallic LnTi-SBA-15 (where Ln is Eu or Pr) photocatalysts were obtained by immobilization of the lanthanide ions on Ti-SBA15 supports synthesized by direct- and postsynthesis methods. The obtained materials were characterized by X-ray diffraction, SEM microscopy, $\mathrm{N}_{2}$ adsorption-desorption and UVVis spectroscopy. The obtained results evidenced an insignificant effect of $\mathrm{Eu}$ and $\mathrm{Pr}$ on support ordered mesoporous structure and optical properties of titania dispersed species. The activity of these photocatalysts was evaluated in the photocatalytic degradation, under UV light $(254 \mathrm{~nm})$, of Brilliant blue FCF from aqueous solutions. A higher activity was obtained for samples with lower loading of lanthanide. The

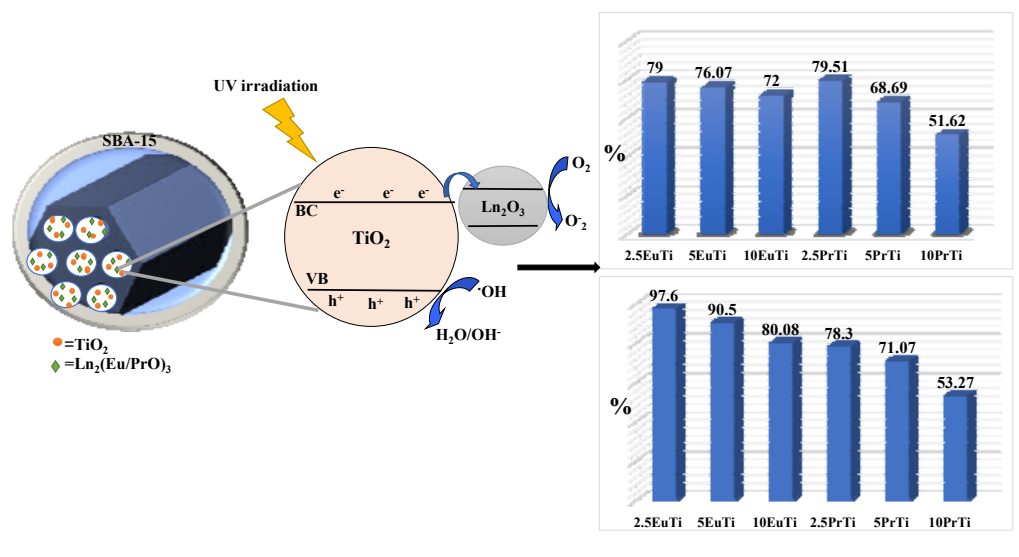
best results were obtained for samples with lowest Eu oxide loading (2.5\%).

\section{INTRODUCTION}

The mesoporous materials generated remarkable progress in the last decades due to their various applications, such as drug supply, ${ }^{1}$ biosensor, ${ }^{2}$ thermal energy storage, ${ }^{3}$ luminescence ${ }^{4}$ and heterogeneous catalysis. ${ }^{5}$ Among the mesoporous materials SBA-15 silica has a wide application in heterogeneous catalysis as support with high surface area, ordered porous structure and high stability. These properties favor dispersion of the supported active species and influence their activity and selectivity. The functionalization of SBA-15 silica with various metals was achieved by several methods, among which direct synthesis and post-synthesis (impregnation) were the most used. These methods have a significant effect on the obtained materials properties..$^{6-8}$ Depending on the synthesis method, different properties were obtained both in the case of the support and of the immobilized metal species. The impregnation method offers the advantage of preparing catalytic materials more easily, because the silica support is put in direct

\footnotetext{
* Corresponding author: vpirvulescu@icf.ro

${ }^{* *}$ Supplementary information on http://web.icf.ro/rrch/ or http://revroum.lew.ro/
} 
contact with the solution of the metal precursor followed by the evaporation of the solvent. ${ }^{9}$ The direct synthesis has the advantage of allowing obtaining more homogeneous dispersion of the heteroatoms, especially by its incorporation into the silica network while by post-synthesis the metal species are deposited, in particular, on the pore surface. Among the transition metals with catalytic activity, titanium has often been used for the functionalization of silica. The activity of titanium oxide, highly dispersed into SBA-15 mesoporous support, in photocatalytic reactions has been improved by doping it with various transition metals. ${ }^{10,11}$ A substantial interest has gained the introduction of $\mathrm{TiO}_{2}$ in the SBA-15 silica network, because mesoporous materials containing titanium species have much larger active surfaces compared to pure $\mathrm{TiO}_{2}$. Different synthesis methods such as sol-gel, hydrothermal or wet impregnation (postsynthesis) allow the modification of SBA-15 materials by immobilization with $\mathrm{TiO}_{2}$. Regarding $\mathrm{TiO}_{2}$ it is the most used semiconductor due to its valuable properties with applications in photocatalysis in the complete elimination of organic pollutants from wastewater and ecological benefits. Wastewater from industries that use dyes endangers the environment due to toxicity to aquatic organisms. Photodegradation processes of the organic and inorganic pollutants from wastewater are a topical issue that uses semiconductor metal oxides. Dyes used in the textile, pharmaceutical, cosmetic and food industries are a major source of environmental contamination. Brilliant Blue FCF is a synthetic dye and is often used in the food, medicine and cosmetic hygiene industries. ${ }^{12} \mathrm{~A}$ special interest can be highlighted regarding the degradation of this dye present as a pollutant in wastewater.

This paper presents the synthesis and properties of $\operatorname{Pr}$ and $\mathrm{Eu}$ impregnated on Ti-SBA-15 new materials in order to obtain mesoporous bimetallic photocatalysts. The obtained materials were characterized by X-ray diffraction, SEM microscopy, $\mathrm{N}_{2}$ adsorption-desorption and $\mathrm{UV}-\mathrm{V}$ is spectroscopy. The activity of these photocatalysts was evaluated in photocatalytic degradation of Brilliant blue FCF from aqueous solutions.

\section{RESULTS AND DISCUSSION}

Figure 1 shows the small angle XRD patterns recorded for the studied samples. For comparison, the XRD pattern of the SBA-15 sample is also illustrated in Fig.1. The parent SBA-15 and the samples obtained by direct synthesis TiSBA-15(sd), 2.5PrTiSBA-15(sd), and 2.5EuTiSBA-15(sd) and impregnation TiSBA-15(i), 2.5PrTiSBA-15(i), and 2.5EuTiSBA-15(i) exhibit three diffraction lines indexed as to (100), (110), and (200) reflections associated to the mesoporous structure with hexagonal symmetry, similar to that observed for the SBA-15 support $^{13}$ (Fig. 1). It is worth noting the preservation of the ordered mesoporous structure of SBA-15 after functionalization. A shift of (100) reflection toward lower angles can be noticed for all modified samples compared to the SBA-15 sample (see inset graph). A less pronounced shift was observed for 2.5EuTi-SBA-15(i), 2.5EuTi-SBA15(sd) and TiSBA-15(i) samples revealing that their ordered mesoporous structure has been retained well after incorporation of $\mathrm{Ti}$ and lanthanide ions. The effect of Ti incorporation into the silica network by direct synthesis was also emphasized on the lattice parameter ${ }^{14}$ and wall thickness ${ }^{15}$ (Table 1).

To evaluate the crystalline behavior of lanthanide species incorporated into SBA-15 structure wide-angle $\mathrm{XRD}$ analysis was performed in the $2 \theta$ range of $10-80^{\circ}$ (Fig. S3). For all samples, no diffraction lines corresponding to lanthanide oxides, even at a concentration of $10 \mathrm{wt} \%$, are observed suggesting a high dispersion of $\mathrm{Pr}$ and $\mathrm{Eu}$ species by the synthesis methods. ${ }^{16}$ Furthermore, the wide angle XRD patterns reveal the presence of anatase phase (JCPDS card no. 021-1272) in all samples besides amorphous $\mathrm{SiO}_{2}$.

The $\mathrm{N}_{2}$ adsorption-desorption isotherms of photocatalysts SBA-15, TiSBA-15 and LnTi-SBA15 are presented in Figure 2. All isotherms are typical for mesoporous SBA-15 silica (type IV) with H1 hysteresis loops according to the IUPAC classification $^{17,18}$.

The incorporation of $\mathrm{Ti}$ by direct synthesis increased the specific surface area $\left(\mathrm{S}_{\mathrm{BET}}\right)$, pore volume $\left(\mathrm{V}_{\mathrm{P}}\right)$ and pore diameter $\left(\mathrm{D}_{\mathrm{P}}\right)$ due to the larger diameter of the titanium cation than that of the silicon (Table 1). Therefore, the incorporation of Ti into SBA-15 network leads to small changes of silica porous structure. In the case of samples obtained by impregnation, the surface area and the pore volume decrease due to $\mathrm{TiO}_{2}$ deposition on pore surface, respectively at the entrance to the pores. ${ }^{19,20}$ The immobilization of lanthanides such as $\mathrm{Eu}^{3+}$ and $\mathrm{Pr}^{3+}$ on TiSBA-15 mesoporous support leads to a more pronounced decrease of textural parameters and insignificant variation of hexagonal ordered porous structure (Table 1). 


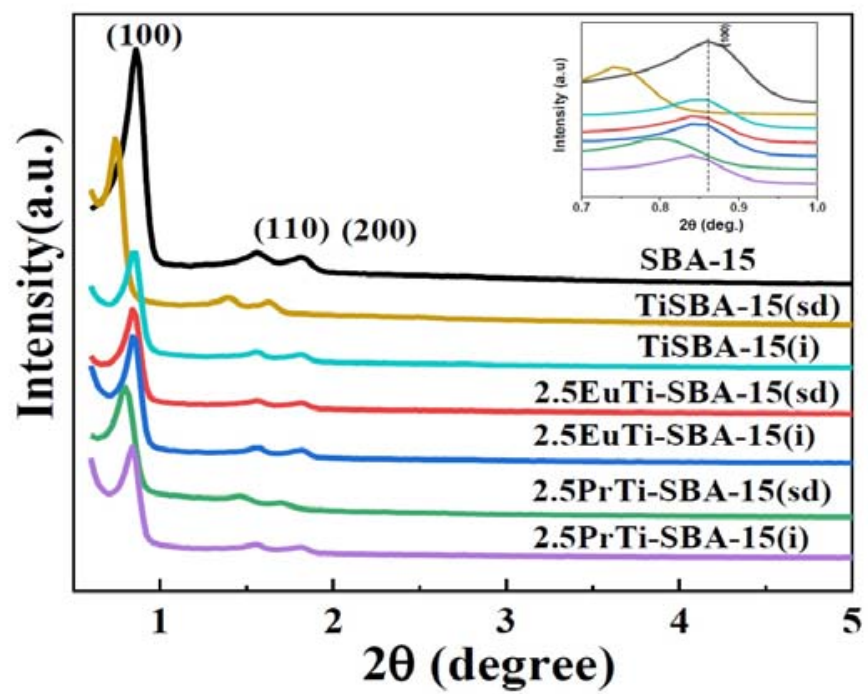

Fig. 1 - XRD patterns of mesoporous SBA-15, TiSBA-15, EuTi-SBA-15 and PrTi-SBA-15 obtained by direct synthesis and impregnation. Insert graph shows the shift of the (100) reflection to lower angles.

Table1

Textural, structural properties and band gap energy of the synthesized samples

\begin{tabular}{l|c|c|c|c|c|c}
\hline \multicolumn{1}{c|}{ Sample } & $\mathbf{S}_{\mathbf{B E T}}, \mathbf{~ m}^{\mathbf{2}} / \mathbf{g}$ & $\mathbf{V p}, \mathbf{c m}^{\mathbf{3}} / \mathbf{g}$ & $\mathbf{D p}(\mathbf{n m})$ & $\mathbf{a}_{\mathbf{0}}(\mathbf{n m})$ & $\mathbf{w}(\mathbf{n m})$ & $\mathbf{E g}(\mathbf{e V})$ \\
\hline SBA-15 & 644.5 & 1.09 & 5.9 & 11.86 & 5.9 & - \\
TiSBA-15(sd.) & 796.2 & 1.2 & 6.4 & 13.79 & 7.3 & 3.16 \\
TiSBA -15(i) & 598.5 & 1.0 & 5.7 & 12.02 & 5.6 & 3.16 \\
2.5PrTi-SBA-15(sd.) & 651.8 & 1.0 & 5.6 & 12.70 & 7.1 & 3.27 \\
2.5PrTi-SBA-15(i.) & 592.2 & 0.8 & 5.3 & 12.18 & 6.8 & 3.17 \\
2.5EuTi-SBA-15(sd) & 586.06 & 0.8 & 5.4 & 13.08 & 7.6 & 3.19 \\
2.5EuTi-SBA-15 (i) & 500.36 & 0.7 & 5.4 & 12.18 & 6.7 & 3.19 \\
\hline
\end{tabular}

$\mathrm{S}_{\mathrm{BET}}$ - specific surface area; $\mathrm{Vp}$ - total pore volume; $\mathrm{Dp}$ - pore diameter, $\mathrm{a}_{0}$ - cell parameter; $\mathrm{w}$ - wall thickness

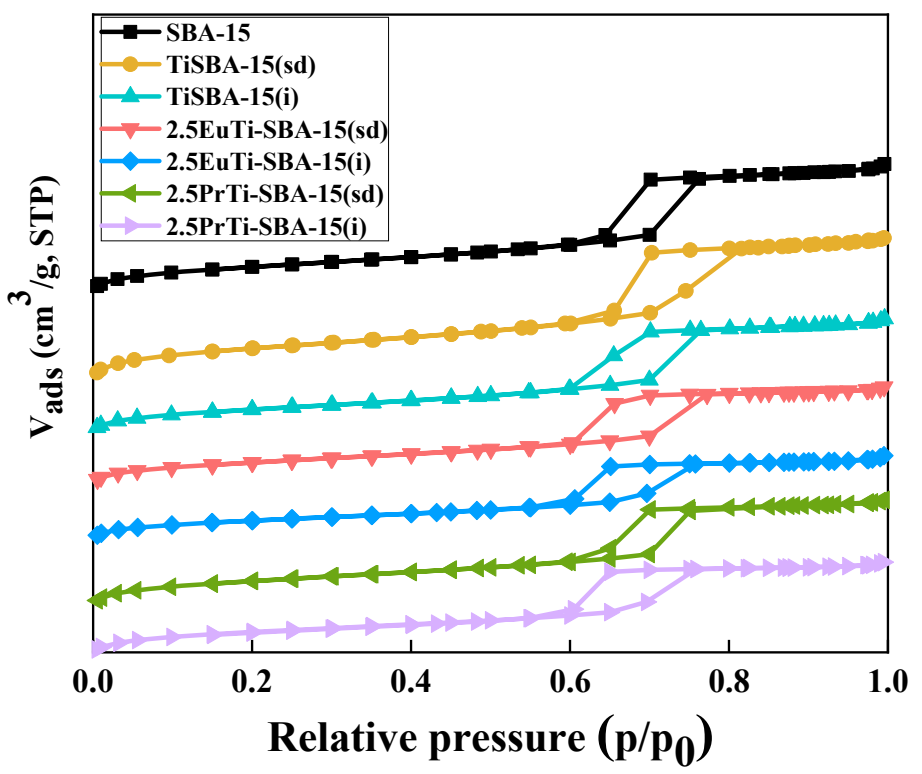

Fig. $2-\mathrm{N}_{2}$ adsorption-desorption isotherms of the synthesized mesoporous materials. 
SEM images show typical rod-like morphologies of the SBA-15 silica. This structure was little influenced in the case of titanium incorporation by direct synthesis (Fig. S1). In the case of all materials obtained using this support,

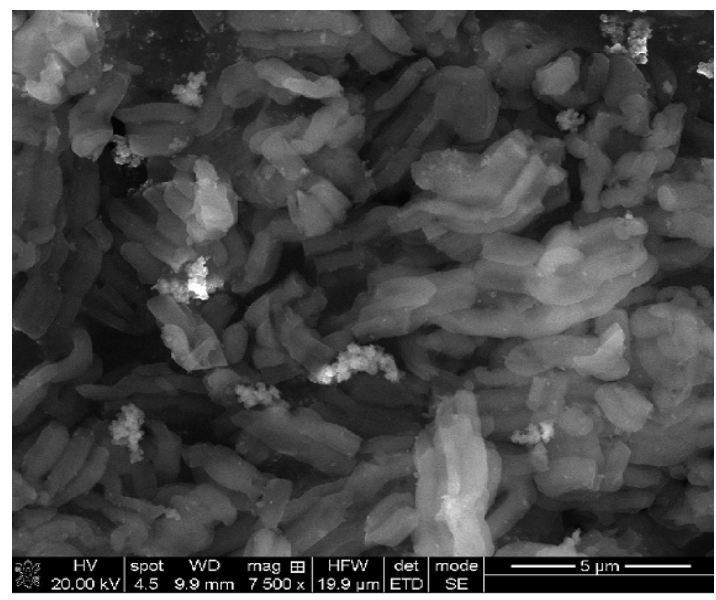

2.5EuTi-SBA-15(sd)

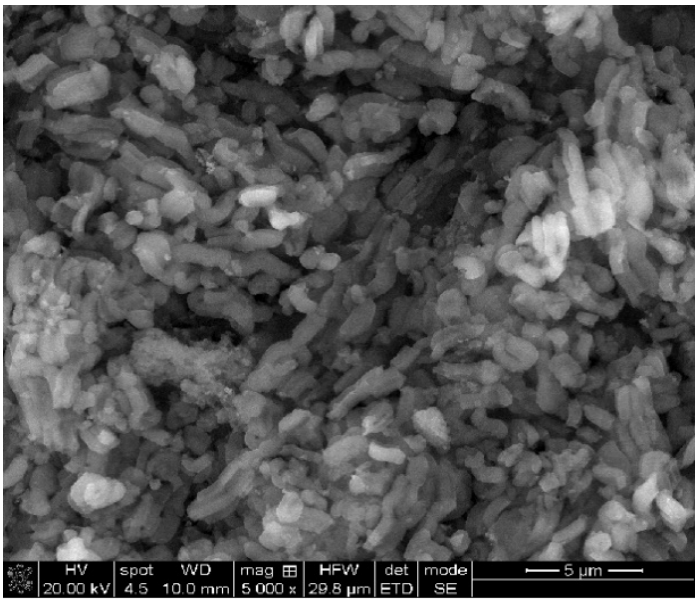

2.5PrTi-SBA-15(sd) the reduction of rods dimensions was observed (Fig. 3). SEM images obatined by BSE microscopy evidence the existence of metal oxide assemblies several dispersed on support surface.

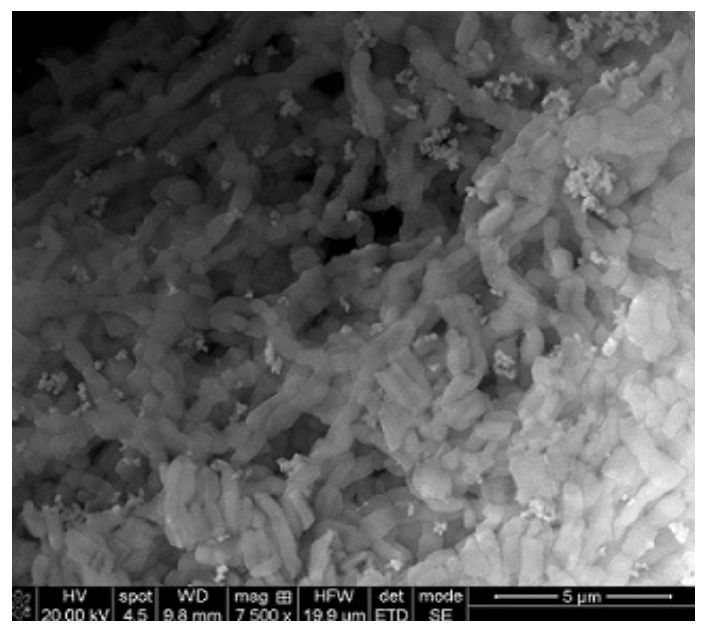

2.5EuTi-SBA-15(i)

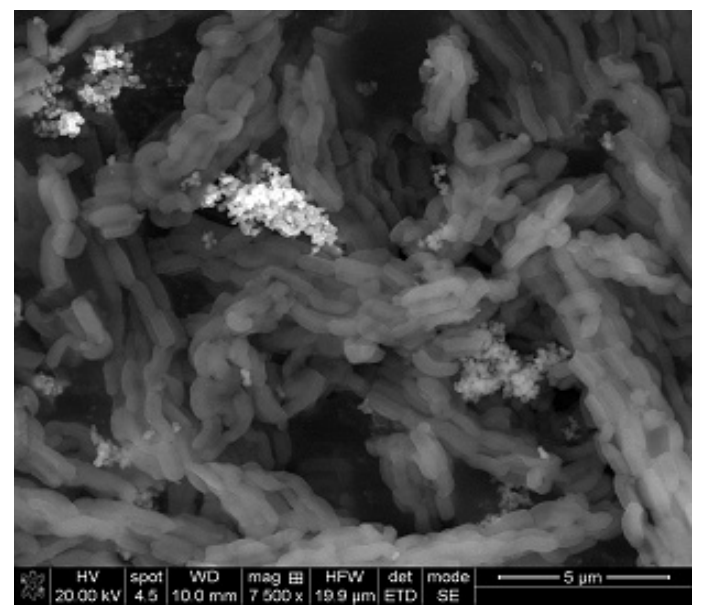

2.5PrTi-SBA-15(i)

Fig. 3 - SEM images of photocatalysts 2.5EuTi-SBA-15(sd), 2.5EuTi-SBA-15(i), 2.5PrTi-SBA-15(sd), 2.5PrTi-SBA-15(i).

UV-Vis spectroscopy is useful tool for determining the oxidation state of various metal species and the coordination around the metal ions. In order to investigate the modification introduced by impregnation with $\mathrm{Eu}$ or $\mathrm{Pr}$, the spectra of bimetallic samples were compared with those of TiSBA-15 samples (Fig. 4). It was observed that the spectra recorded for all samples present two bands, at $260 \mathrm{~nm}$ and $290 \mathrm{~nm}$, attributed to the polymerized tetrahedrally coordinated $\left(\mathrm{TiO}_{4}\right.$ units $)$ and, respectively, octahedral coordinated $\mathrm{Ti}$ species. ${ }^{21,22}$ UV-Vis diffuse reflection spectra for the samples impregnated with $\mathrm{Eu}$ and $\mathrm{Pr}$ respectively (Fig. 4) indicate a decrease of the absorbance intensity for all the samples except for 2.5PrTi-SBA-15. It is also observed the appearance of a shoulder at $325 \mathrm{~nm}$ (more significant in the case of samples with Pr), which can be attributed to the formation of anatase. ${ }^{22}$ The spectra of samples obtained by direct synthesis present lower absorbance and the tetrahedrally species are mainly isolated (absorption at $220 \mathrm{~nm}^{21}$ ). In Fig. 5 it was presented the UV-VIS spectra obtained for 5\% and $10 \%$ Pr-containing samples at wavelength higher than $400 \mathrm{~nm}$, used to highlighted the presence of $\operatorname{Pr}^{3+}$ ions, which characteristic bands at 444, 469, $482 \mathrm{~nm}$ and $588 \mathrm{~nm}^{23}$ 

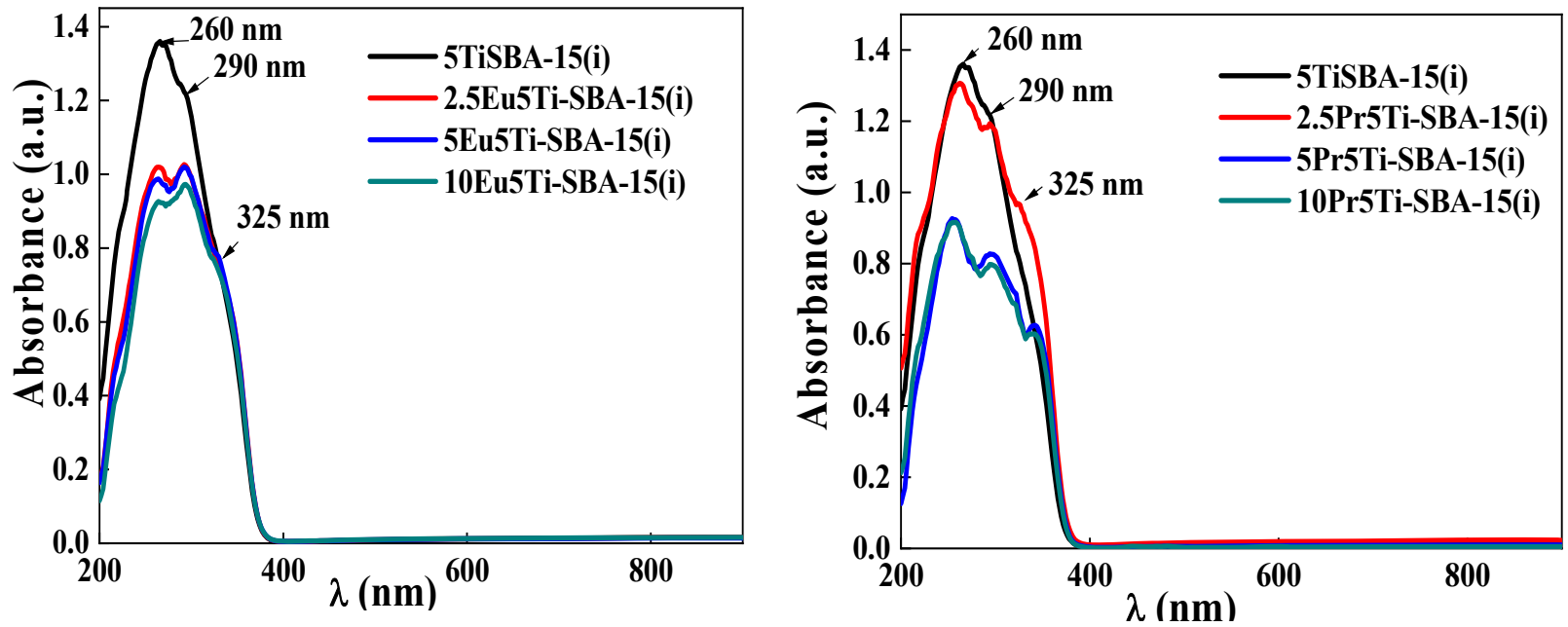

Fig. 4 - UV-Vis absorption spectra of bimetalic samples with Eu and Pr.

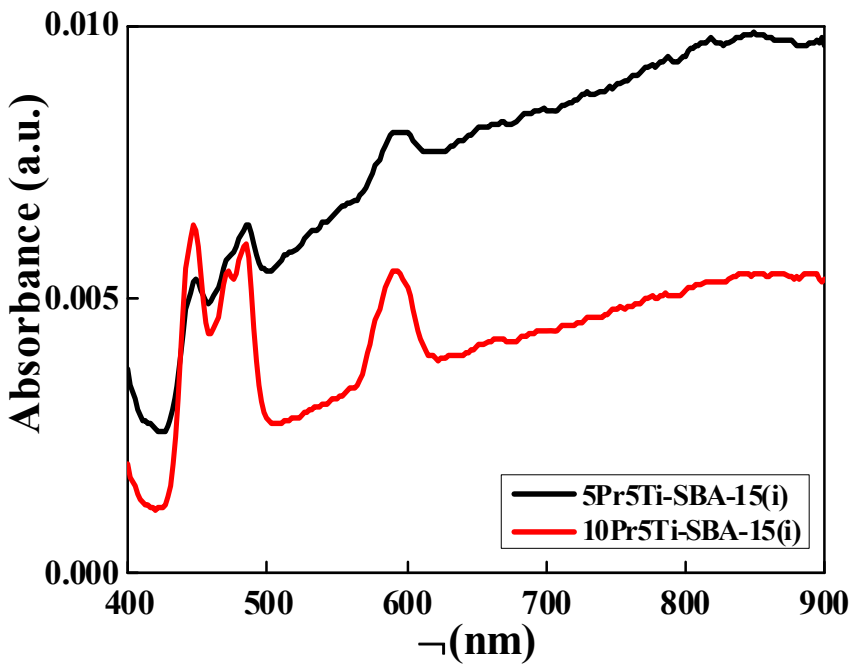

Fig. 5 - UV-Vis absorption spectra of 5PrTi-SBA15 and 10PrTi-SBA15 samples between 400-900 nm.
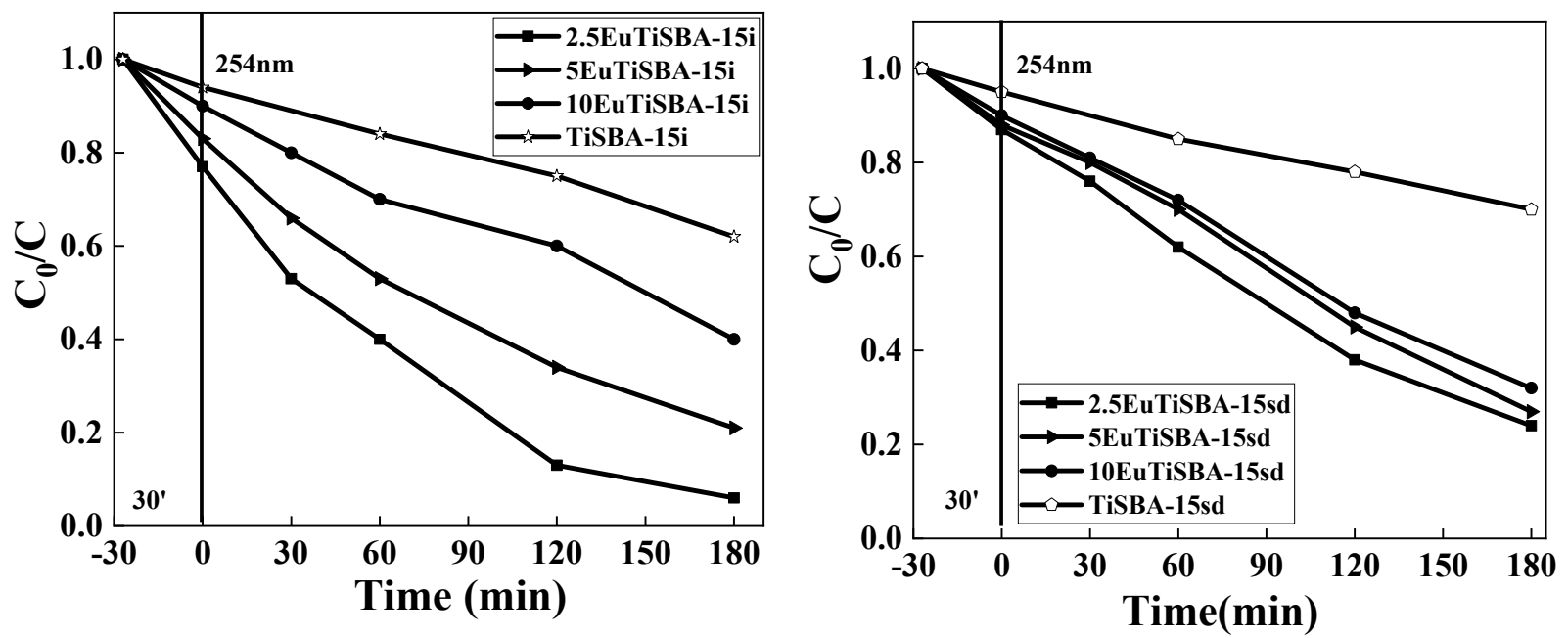

Fig. 6 - The variation in time of the photocatalytic efficiency obtained for EuTi-SBA-15(i) and EuTi-SBA-15(sd) samples in degradation of the Brilliant Blue FCF dye. 

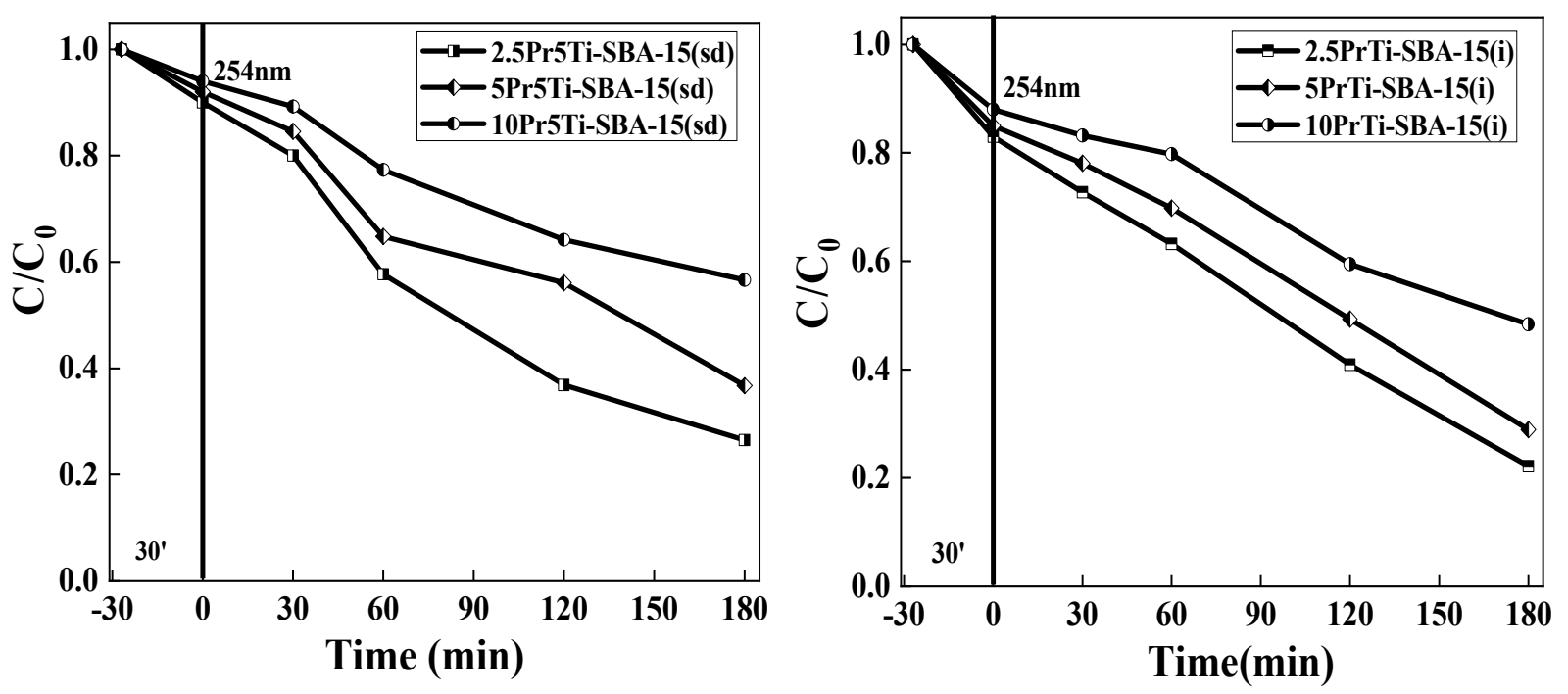

Fig. 7 - The variation in time of the photocatalytic efficiency obtained for PrTi-SBA-15(i) and PrTi-SBA-15(sd) samples in degradation of the Brilliant Blue FCF dye.

In order to determine the effect of the synthesis method and of the impregnation with lanthanide ions on the optical properties of the obtained materials, the values of the optical band gap energies were also calculated (Table 1). For this purpose, it was used Tauc relation, representing graphically $(\mathrm{F}(\mathrm{R}) \mathrm{h} v)^{1 / \eta}$ vs $\mathrm{h} v$ (Fig. S2) where $\eta=1 / 2$ (specific to indirect allowed transitions). The band gap was obtained from the extrapolation to the abscissa of the linear region. It can see that the values of the band gap energies do not depend on the preparation method and, more than that, they remain almost unchanged after addition of $\mathrm{Eu}$ or Pr. Under these conditions the main effect of Pr or $\mathrm{Eu}$ addition is the reduction of electron-hole recombination in irradiated $\mathrm{TiO}_{2}$, thus increasing the efficiency of photocatalysts.

The photocatalytic efficiency of the obtained materials was evaluated in degradation of the Brilliant blue FCF dye from aqueous solution. The performances of EuTi-SBA-15 samples, obtained by impregnation and direct synthesis are presented in Fig. 6. In similar conditions were tested the samples with $\mathrm{Pr}$, and the results obtained are shown in Figure 7.

Compared to EuTi-SBA-15(i) samples a lower efficiency was obtained for PrTi-SBA-15(i) samples. This may be the result of lower band gap values of $\mathrm{Eu}_{2} \mathrm{O}_{3}(2.4 \mathrm{eV})$ compared to that of $\mathrm{Pr}_{2} \mathrm{O}_{3}$ $(3.8 \mathrm{ev})$. The higher performance of the samples obtained by impregnation of $\mathrm{Ti}$ is due to its dispersion on the surface, the significant values of absorption at $365 \mathrm{~nm}$ (irradiation light) and the effect of dispersed lanthanide oxide at lower concentration $(2.5 \%)$.

\section{EXPERIMENTAL}

\section{Materials}

The reagents used in the synthesis were: the block copolymer surfactant $\mathrm{EO}_{20} \mathrm{PO}_{70} \mathrm{EO}_{20}$ (Pluronic P123, Mn $\sim 5,800$ ), hydrochloric acid solution (37\%), Praseodymium (III) nitrate hexahydrate $99.9 \%$, Europium (III) nitrate hexahydrate $99.9 \%$, were purchased from Sigma Aldrich, Titanium butoxide (TBOT) Acros Organics, Tetraetilortosilicat (TEOS) Merck, dye Brilliant Blue FCF were purchased Dr. Oetker.

\section{Preparation of Ti-SBA-15} and Eu/PrTi-SBA-15 photocatalysts

Ti-SBA-15 samples were obtained by direct-synthesis and post-synthesis methods. ${ }^{24}$

The bimetallic photocatalysts EuTi-SBA-15 and PrTiSBA-15 were obtained by impregnation of lanthanide precursors $\left(\mathrm{Eu}\left(\mathrm{NO}_{3}\right)_{3}\right.$ and $\operatorname{Pr}\left(\mathrm{NO}_{3}\right)_{3}$, respectively) on Ti-SBA15 supports. The materials were obtained with the same concentrations of europium / praseodymium. The concentration of metal salts was calculated taking into account the value of the determined impregnation capacity and the desired final concentration of lanthanides oxide deposited : $2.5 \mathrm{wt} \% ; 5 \mathrm{wt} \%$ and $10 \mathrm{wt} \%$. After impregnation, the materials were dried for 24 hours at room temperature. The final product obtained was dried at $80^{\circ} \mathrm{C}$ in the oven, then calcined at $550^{\circ} \mathrm{C}$ for 8 hours in air.

\section{Characterization of Materials}

X-ray diffraction spectra were recorded using a Rigaku Ultima IV diffractometer by using $\mathrm{CuK}_{\alpha}$ radiation $(\lambda=0.1541$ $\mathrm{nm}) . \mathrm{N}_{2}$ adsorption-desorption measurements were carried out at $-196^{\circ} \mathrm{C}$ using a Micromeritics ASAP 2020 automated gas 
adsorption analyzer. The morphology of the sample was investigated by scanning electron microscopy (SEM) using a high-resolution microscope, FEI Quanta 3D FEG model and UV-vis spectra were recorded on PERKIN LAMBDA 35 Spectrophotometer.

Nitrogen physisorption measurements were carried out at $196^{\circ} \mathrm{C}$ using a Micromeritics ASAP 2020 automated gas adsorption analyzer. The samples were degassed at $250^{\circ} \mathrm{C}$ for 4 hours under vacuum before analysis. Specific surface areas $\left(\mathrm{S}_{\mathrm{BET}}\right)$ were calculated according to the Brunauer-EmmettTeller (BET) equation, using adsorption data in the relative pressure range between 0.05 and 0.30 . The total pore volume $\left(\mathrm{V}_{\text {total }}\right)$ was estimated from the amount adsorbed at the relative pressure of 0.99 . The average pore diameter was obtained using Barrett-Joyner-Halenda (BJH) method from the desorption branch.

\section{Photocatalytic properties}

Aqueous solutions of concentration $1 \times 10^{-5} \mathrm{M}, 1.5 \mathrm{mg}$ of catalyst and quartz mini-reactors were used for the photocatalytic degradation of FCF Blue Brilliant. The reactions were carried out in quartz reactors, under magnetic stirring, at room temperature and in presence of UV radiation lamp (filter for $\lambda=254 \mathrm{~nm}$ ). Time of reaction was varried between $60-180$ min. The photocatalytic properties were evaluated from degree of dye degradation. No analysis of the reaction products was performed. The variation of sample absorption was evaluated with a Perkin Lambda 35 spectrophotometer at different irradiation times. To determine the photodegradation efficiency of Brilliant Blue FCF, the absorbance value was measured at the wavelength corresponding to the maximum absorption of FCF Blue Brilliant dye $(628 \mathrm{~nm})$. The photocatalytic activity of photocatalysts was evaluated quantitatively by determining the efficiency of dye degradation $\left(\mathrm{E}_{\mathrm{D}} \%=\left(\mathrm{C}_{0}-\mathrm{C}\right) / \mathrm{C}_{0} * 100=\left(\mathrm{A}_{0}\right.\right.$ A) $\left./ A_{0} * 100\right)$ where $A_{0}$ is absorbance measured solutions before irradiation and $\mathrm{A}$ the absorbance of the solutions at time $\mathrm{t}$ after irradiation. ${ }^{25}$ No analysis of degradation products has been done.

Prior to irradiation with UV light, the suspensions were magnetically stirred in the absence of light for $30 \mathrm{~min}$ to establish the adsorption-desorption equilibrium. The suspension was then irradiated with UV light at a constant stirring speed.

\section{CONCLUSIONS}

New bimetallic LnTi-SBA-15 (where Ln is Eu or Pr) photocatalysts with typical SBA-15 ordered mesoporous structure were prepared by two methods of titania immobilization. Ti-SBA-15 mesoporous supports, obtained by direct - or post synthesis method, were impregnated with Eu or Pr. The photocatalytic performances of these materials were evaluated in Brilliant Blue FCF dye degradation from water. The best results were obtained for samples with lowest Eu loading and Ti immobilized by impregnation. The efficiency of the photocatalytic degradation decreased, for all the samples, with lanthanide loading.

\section{REFERENCES}

1. V. F. Vavsari, G. M. Ziarani and A. Badiei, RSC $A d v$., 2015, 5, 91686-91707.

2. Z. Bagheryan, J. B. Raoof, R. Ojani and P. Rezaei, Talanta, 2014, 119, 24-33.

3. T. Kadoono and M. Ogura, Phys.Chem. Chem. Phys., 2014, 28, 5495-5498.

4. Y. Li, B. Yan and H. Yang, J. Phys. Chem. C, 2008, 112, 3959-3968.

5. A. M. Busuioc, V. Meynen, E. Beyers, M. Mertens, P. Cool, N. Bilba and E. F. Vansant, Appl. Catal. A: Gen., 2006, 312, 153-164.

6. Z. A. ALOthman, Materials, 2012, 5, 2874-2902.

7. F. Juan and E. R. Hitzky, Adv. Materials, 2000, 12, 430432.

8. Z. Dan and L. J. Hua, Chinese Sci. Bull., 2013, 58, 879883.

9. A. van Dillen, R. J. A. M. Terörde, D. J. Lensveld, J. W. Geus and K. P. Jong, J. Catal., 2003, 216, 257-264.

10. P. H.Nguyen, T. V. H. Nguyen and V. N. Nguyen, Nanosci. Nanotech., 2013, 3,19-25.

11. Z. M. El-Bahy, A. A. Ismail and R. M. Mohamed, $J$. Hazard. Mater., 2009, 166, 138-143.

12. J. Guo, H. Wu, L. Du and Y. Fu, Anal. Methods, 2013, 5, 4021-4026.

13. L. Yang, Z. Jiang, S. Lai, C. Jiang and H. Zhong, Int. J. Chem. Eng., 2014, 1-7.

14. K. Lin, P. P. Pescarmona, H. Vandepitte, D. Liang, G. V. Tendeloo and P. A. Jacobs, J. Catal., 2008, 254, 64 .

15. M. K. Naskar and M. Eswaramoorthy, J. Chem. Sci., 2008, $120,181$.

16. C. Lin, K. Tao, H. Yu, D. Hua and S. Zhou, Catal. Sci. Technol., 2014, 4, 4010.

17. M. Thommes, Chem. Ing. Technik, 2010, 82, 1059-1073.

18. Y. J. A. Silva, R. Nava, V. H. Morales, S. A. M. Sanchez, M. L. G. Herrera and B. Pawelec, Appl. Catal. B. Environ. 2011, 110, 108- 117.

19. T. Olejnik, S. P. Patkowska, A. Lesiuk and J. Ryczkowski, Pol. J. Chem. Technol., 2016, 18, 30-38.

20. T. Diaconu, M. Ciobanu, G. Petcu, D. Culita, S. Preda, J. P. Cusu, M. Mureseanu and V. Parvulescu, Rev. Roum. Chim., 2018, 63, 467-474.

21. A. Wroblewska, P. Miadlicki, J. S. Nazzal, M. Sadlowski, Z. C. Koren and B. Michalkiewicz, Micropor. Mesopor. Mater., 2018, 258, 72-82.

22. K. M. Choi, T. Yokoi, T. Tatsumi and K. Kuroda, J. Mater. Chem. A, 2013, 1, 2485-2494.

23. M. A. Malecka and L. Kepinski, J. Alloy and Compounds, 2007, 430, 282-291.

24. M. Filip, G. Petcu E.M. Anghel, S. Petrescu, B.Trica, P. Osiceanu, N. Stanica, I. Atkinson, C. Munteanu, M. Mureseanu and V. Parvulescu, Catal. Today, in press, 10.1016/j.cattod.2020.08.003.

25. S. Li, Q. Lin, X. Liu, L. Yang, J. Ding, F. Dong, Y. Li, M. Irfana and P. Zhang, RSC $A d v$., 2018, 8, 2027720286 . 
